\title{
APLIKASI KAMERA PENDETEKSI MOBIL Menggunakan Pendekatan Pengolahan Citra
}

\author{
Duman Care Khrisne \\ Dosen Sistem Komputer \\ STMIK STIKOM Indonesia \\ Denpasar-Bali, Indonesia \\ duman_lx14[at]yahoo.com
}

\author{
I Made Yudi Adnyana Putra \\ Mahasiswa Sistem Komputer \\ STMIK STIKOM Indonesia \\ Denpasar-Bali, Indonesia \\ adek_adnyana[at]yahoo.co.id
}

\begin{abstract}
Teknologi pengenalan pola banyak digunakan di berbagai aplikasi keamanan. Dalam penelitian ini mencoba menerapkan pengenalan pola untuk mengidentifikasi objek mobil dan bukan mobil. Penelitian ini bertujuan untuk mensimulasikan metode pengolahan citra untuk mengidentifikasi jenis objek yang masuk ke dalam frame webcam sebagai simulasi kamera pengawas.

Input dari aplikasi adalah citra yang diakuisisi dari stream webcam, kemudian di lakkukan proses ekstraksi fitur bentuk menggunakan momen invarian dan ekstraksi fitur tekstur menggunakan Wavelet Haar. Fitur-fitur yang diperoleh kemudian dilatih dengan model jaringan saraf tiruan metode Learning Vector Quantization (LVQ). LVQ menghasilkan bobot setiap kelas, bobot dari hasil pelatihan LVQ akan menentukan kelas dari ciri objek yang diuji. Percobaan dilakukan dengan mengumpulkan data berupa foto objek mobil dan objek bukan mobil. Dari data yang dikumpulkan kemudian dikelompokkan berdasarkan jenis objek berupa mobil atau bukan mobil. Hasil pengujian menunjukan keberhasilan sebesar rata-rata dapat mengenali sampai 80\% baik untuk data uji dari dalam data latih maupun data uji dari luar data latih.
\end{abstract}

Keywords-webcam; LVQ; pengolahan citra; mobil; pengenalan pola

\section{PENDAHULUAN}

Kamera pengawas sering dijumpai pada sistem-sistem keamanan, kamera pengawas adalah wakil dari visual manusia yang berada di lapangan. Dengan memasang kamera pengawas pada tempat-tempat yang memerlukan pengawasan di suatu areal gedung atau perkantoran, maka perusahaan tersebut dapat diuntungkan dari segi jumlah petugas keamanan yang dibutuhkan. Petugas keamanan yang menjadi operator dari kamera pengawas tersebut cukup standby di pusat kendali. Kamera pengawas juga telah difungsikan pada lapangan parkir. Sistem kamera pengawas ini dapat digunakan untuk mendeteksi keluar masuknya mobil, sehingga operator tidak harus selalu berada di depan pintu masuk sebuah areal parkir.

Kinerja kamera akan sangat efektif jika operator dapat mengawasi dan mengoperasikannya selama 24 jam. Namun tenaga manusia terbatas, selain itu manusia mempunyai tingkat kejenuhan untuk melakukan sesuatu yang sama setiap harinya sehingga meningkatkan resiko terjadinya kelalaian manusia (human error). Manusia dalam mengoperasikan kamera masih banyak kekurangan dan keterbatasan kemampuan karena tidak selamanya dapat mangawasi kinerja kamera secara maksimal.

Dari uraian di atas, perlu adanya bantuan sebuah aplikasi komputer untuk membantu kinerja operator dalam pemanfaatan fungsi kamera secara maksimal. Dari penelitian sebelumnya, Amelia, M sarwoko dan Tengku Ahmad Riza [1] pada penelitian berjudul Perancangan Sistem Deteksi Kendaraan Bermotor yang bertujuan untuk membedakan kendaraan bermotor dengan Bus Trans Jakarta, menggunakan webcam, mikrokontroler ATMEGA 8535 dan Sensor ultrasonik pada juni tahun 2013. Penelitian ini melakukan deteksi terhadap kendaraan yang meintas pada jalur transjakarta dengan output berupa gambar kendaraan yang bukan bus transjakarta namun melintas melalui jalur transjakarta. Gambar ini disebut sebagai gambar warning atau gambar pelanggaran, beberapa gambar dapat diambil dengan kecepatan sekitar 1 sampai 2 detik. Penelitian sejenis juga dilakukan oleh Setiawan Hadi dan Yoeshua Rekha Samara [2] dalam penelitiannya yang berjudul Deteksi Objek Kendaraan pada Citra Dijital Jalan Raya Menggunakan Metode Visi Komputer. Penelitian ini adalah penelitian pada Hibah Fundamental 2011-2012 dengan nomor kontrak DIPA DIKTI 0541/023-04.1/00/2011, memanfaatkan 
pendekatan pengolahan citra dengan gabungan metode Hough Transform dan Connected Component Labeling. Hasil dari penelitian ini adalah aplikasi yang dapat mendeteksi kendaraan pada sebuah dasar citra jalan raya dengan akurasi pendeteksian kendaraan sampai dengan $79.46 \%$

Penelitian sebelumnya telah menunukkan bahwa aplikasi pengolahan citra dapat digunakan untuk melakukan deteksi kendaraan, maka pada penelitian ini dibangun sebuah aplikasi untuk membedakan kendaraan yang masuk ke areal parkir menjadi kelas mobil atau bukan mobil. Aplikasi yang dibangun menggunakan asas pengolahan citra yang mengolah sebuah frame dari hasil tangkapan visual pada waktu tertentu yang dilakukan oleh kamera pengawas. Ekstraksi ciri dari gambar dilakukan dengan gabungan dua buah metode Momment Invarian dan Wavelet Haar. Fitur yang dihasilkan menjadi data latih untuk sebuah model klasifikasi menggunakan jaringan saraf tiruan, Learning Vector Quantization (LVQ).

\section{CIRI BENTUK MENGGUNAKAN MOMEN INVARIAN}

\section{A. Mommen}

Momen (moment) dapat menggambarkan suatu objek dalam hal area, posisi, orientasi dan parameter terdefinisi lainnya. Persamaan dasar dari momen suatu objek menurut [3] didefinisikan sebagai persamaan (1).

$$
\mathbf{m}_{\mathrm{ij}}=\sum_{\mathrm{x}} \sum_{\mathrm{y}} \mathbf{x}^{\mathrm{i}} \mathbf{y}^{\mathrm{j}} \mathbf{a}_{\mathbf{x y}}
$$

Dimana $m$ adalah momen suatu objek, $i$ dan $j$ adalah ordo dari momen, $x$ dan $y$ menyatakan koordinat pixel, sedangkan $\mathrm{a}_{x y}$ menyatakan intensitas pixel.

\section{B. Mommen Invarian}

Dari momen ternormalisasi diatas, sekumpulan momen invarian (invariant moments) dapat didefinisikan. Momen-momen ini sangat berguna dalam pembuatan vektor ciri untuk pengenalan objek. Berikut ini adalah persamaan dari momenmomen invarian [4].

$$
\begin{aligned}
& \Phi_{1}=\eta_{20}+\eta_{02} \\
& \Phi_{2}=\left(\eta_{20}+\eta_{02}\right)^{2}+4 \eta_{11}^{2} \\
& \Phi_{3}=\left(\eta_{30}+3 \eta_{12}\right)^{2}+\left(3 \eta_{21}+\eta_{03}\right)^{2} \\
& \Phi_{4}=\left(\eta_{30}+\eta_{12}\right)^{2}+\left(\eta_{21}+\eta_{03}\right)^{2} \\
& \Phi_{5}=\left(\eta_{30}+3 \eta_{12}\right)\left(\eta_{30}+\eta_{12}\right) \\
& \left\{\left(\eta_{30}+\eta_{12}\right)^{2}-3\left(\eta_{21}+\eta_{03}\right)^{2}\right\}+
\end{aligned}
$$

$$
\begin{aligned}
& \left(3 \eta_{21}-\eta_{03}\right)\left(\eta_{21}+\eta_{03}\right) \\
& \left\{3\left(\eta_{30}+\eta_{12}\right)^{2}-\left(\eta_{21}+\eta_{03}\right)^{2}\right\} \\
& \Phi_{6}=\left(\eta_{20}-\eta_{02}\right) \\
& \left\{\left(\eta_{30}+\eta_{12}\right)^{2}-\left(\eta_{21}+\eta_{03}\right)^{2}\right\}+ \\
& 4 \eta_{11}\left(\eta_{30}+\eta_{12}\right)\left(\eta_{21}+\eta_{03}\right) \ldots \ldots \ldots \\
& .(7) \\
& \Phi_{7}=\left(3 \eta_{21}-\eta_{30}\right)\left(\eta_{30}+\eta_{12}\right) \\
& \left\{\left(\eta_{30}+\eta_{12}\right)^{2}-3\left(\eta_{21}+\eta_{03}\right)^{2}\right\} \\
& \left(3 \eta_{21}-\eta_{03}\right)\left(\eta_{21}+\eta_{03}\right) \\
& \left\{3\left(\eta_{30}+\eta_{12}\right)^{2}-\left(\eta_{21}+\eta_{03}\right)^{2}\right\}
\end{aligned}
$$

Dengan $\Phi$ melambangkan momen invarian dan $\eta_{x y}$ menyatakan momen pusat ternormalisasi dengan ordo $x$ dan $y$.

\section{CIRI TEKSTUR MENGGUNAKAN ALIH RAGAM GELOMBANG SINGKAT (WAVELET)}

\section{A. Gelombang Singkat (Wavelet)}

Alihragam gelombang singkat (wavelet) merupakan alihragam yang membawa citra (signal) ke versi pergeseran (shifted) dan penskalaan (scaled) dari gelombang singkat yang asli (mother wavelet). Alihragam gelombang singkat diskrit dapat dilakukan dengan suatu pentapisan bertingkat (cascading filter), yang diikuti dengan pencuplikan (subsampling) dengan pembagian 2 [5]. Gambar 1 menunjukkan bagan alihragam gelombang singkat diskrit.

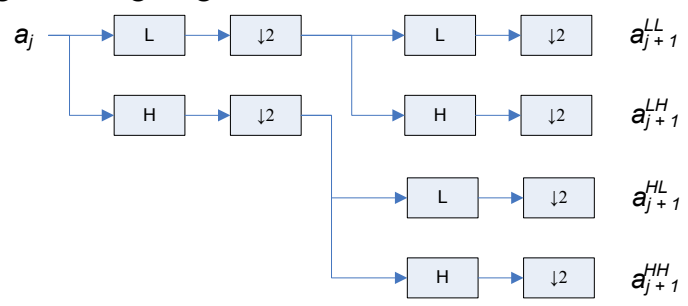

Gambar 1 Alihragam Wavelet Diskrit pada Citra 2 Dimensi Sumber : [4]

$\mathrm{H}$ dan $\mathrm{L}$ berturut-turut menyatakan tapis yang meneruskan frekuensi tinggi (high-pass filter) dan tapis yang meneruskan frekuensi rendah (low-pass filter). $\downarrow 2$ menyatakan pencuplikan dengan pembagian 2. Keluaran dari tapis diberikan melalui persamaan berikut [4]

$$
\begin{aligned}
& a_{j+1}=\sum_{n}^{n} 1[n-2 p] a_{j}[n] \\
& d_{j+1}=\sum_{n} h[n-2 p] a_{j}[n]
\end{aligned}
$$


Elemen $a_{j}$ yang digunakan untuk tahap berikutnya disebut dengan elemen penskalaan dan elemen $d_{j}$ disebut dengan koefisien gelombang singkat, yang merupakan alihragam. Jumlah elemen pada skala $j+1$ adalah setengah dari jumlah elemen a dan d pada skala j. Hal ini mengakibatkan alihragam gelombang diskrit hanya bisa dilakukan sampai tersisa dua elemen aj (untuk gelombang singkat Haar). Elemen ini disebut koefisien fungsi skala. Untuk jenis gelombang singkat Haar, nilai tapis $\mathrm{L}=[0.7071,0.7071], \mathrm{H}=[-0.7071,0.7071]$.

\section{B. Energi dan Standar Deviasi Subband}

Fitur citra hasil transformasi wavelet diskrit dapat diperoleh dengan menghitung energi yang terkandung pada setiap subband. Pada setiap skala, suatu citra terbagi menjadi 4 subband yang ditunjukkan seperti pada gambar 2 .

\begin{tabular}{|c|c|c|}
\hline$d_{2}{ }^{\mathrm{LL}}$ & $\mathrm{d}_{2}{ }^{\mathrm{HL}}$ & \multirow{2}{*}{$\mathrm{d}_{1}{ }^{\mathrm{HL}}$} \\
\cline { 1 - 2 } $\mathrm{d}_{2}{ }^{{ }^{\mathrm{HH}}}$ & $\mathrm{d}_{2}{ }^{\mathrm{HH}}$ & \\
\hline $\mathrm{d}_{1}{ }^{\mathrm{LH}}$ & \multirow{2}{*}{$\mathrm{d}_{1}{ }^{\mathrm{HH}}$} \\
\hline
\end{tabular}

Gambar 2 Pembagian subband pada citra hasil dekomposisi

Sumber : [4]

Energi setiap subband [5] dapat dihitung dengan persamaan (11) dimanan $E$ adalah energi yang mewakili setiap subband sedangkan $d_{x y}$ adalah intensitas pixel dalam sebuah subband pada koordinat $(x, y)$ dan $n$ adalah jumlah titik dalam sebuah subband.

$$
E_{\text {subband_scale }}=\frac{\sum_{x, y}\left(d_{x, y}^{\text {subband }}\right)}{n}
$$

Sedangkan standar deviasi [5] untuk setiap subband dapat dihitung menggunakan persamaan (12).

$$
S_{\text {subband_scale }}=\sqrt{\left(\sum_{x, y}\left(d_{x, y}^{\text {subband }}\right)-\frac{\sum_{x, y}\left(d_{x, y}^{\text {subband }}\right)}{n}\right)}
$$

dengan $S$ adalah standar deviasi yang mewakili setiap subband, $d_{x y}$ adalah intensitas pixel dalam sebuah subband pada koordinat $(x, y)$ dan $n$ menyatakan jumlah titik pada setiap subband.

\section{IV.LEARNING VECTOR QUANTIZATION (LVQ)}

LVQ merupakan suatu metode untuk melakukan pembelajaran pada lapisan kompetitif yang ter-supervisi (supervised). Suatu lapisan kompetitif secara otomatis belajar untuk mengklasifikasikan vektor-vektor input. Jika dua vektor input mendekati sama, maka lapisan kompetitif meletakkan kedua vektor input tersebut ke dalam kelas yang sama. Jadi LVQ adalah metode untuk klasifikasi (pengelompokan) pola dan memiliki output yang mewakili kelas tertentu. Bobot vektor untuk sebuah layer output sering berfungsi sebagai vektor referensi untuk kelas dimana layer ditampilkan. Dalam pelatihan, layer output ditempatkan dengan mengatur bobot sepanjang pelatihan, untuk memperkirakan keputusan dari teori klasifikasi. Hal ini diasumsikan sebagai satu set dari pola pelatihan dengan klasifikasi yang disediakan. Sepanjang sebuah distribusi inisial atau vektor referensi (masing-masing melambangkan klasifikasi yang diketahui) [6].

LVQ menggunakan pendekatan Self Organizing Map (SOM) dimana terdapat training vektor yang secara rekursif mengoptimasi penempatan hidden layer yang saling berkompetisi. Sebuah vektor masukan dikelompokkan ke dalam kelas, dimana kelas tersebut adalah representasi dari hidden layer yang terdekat, terhadap vektor input. Pembelajaran pada LVQ dilakukan dengan memasukkan vektor input dan menyesuaikan lokasi hidden layer berdasarkan kedekatannya terhadap vektor tersebut. Hidden layer terdekat dipindahkan (secara proporsional terhadap tingkat pembelajaran) mendekati training vektor jika kelas hidden layer dan training vetornya cocok, dan menjauhi training vektor jika sebaliknya [7].

\section{A. Data Penelitian}

\section{RANCANGAN APLIKASI}

Data yang digunakan dalam penelitian ini berupa gambar mobil dan bukan mobil dicetak pada kertas gambar A4 berukuran $21 \mathrm{~cm} \mathrm{X} \mathrm{29,7}$ $\mathrm{cm}$. Data latih menggunakan 6 gambar objek mobil dan 6 gambar objek bukan mobil yang berbeda-beda yang dapat dilihat pada Tabel 1 . Untuk tahap pengujian menggunakan 3 sampel gambar mobil dan gambar bukan mobil yang diambil dari dalam data latih dan 3 sampel gambar mobil dan gambar bukan mobil yang diambil dari luar data latih. 
TABEL 1 Data LatiH Berupa Mobil DaN BUKAN MOBIL

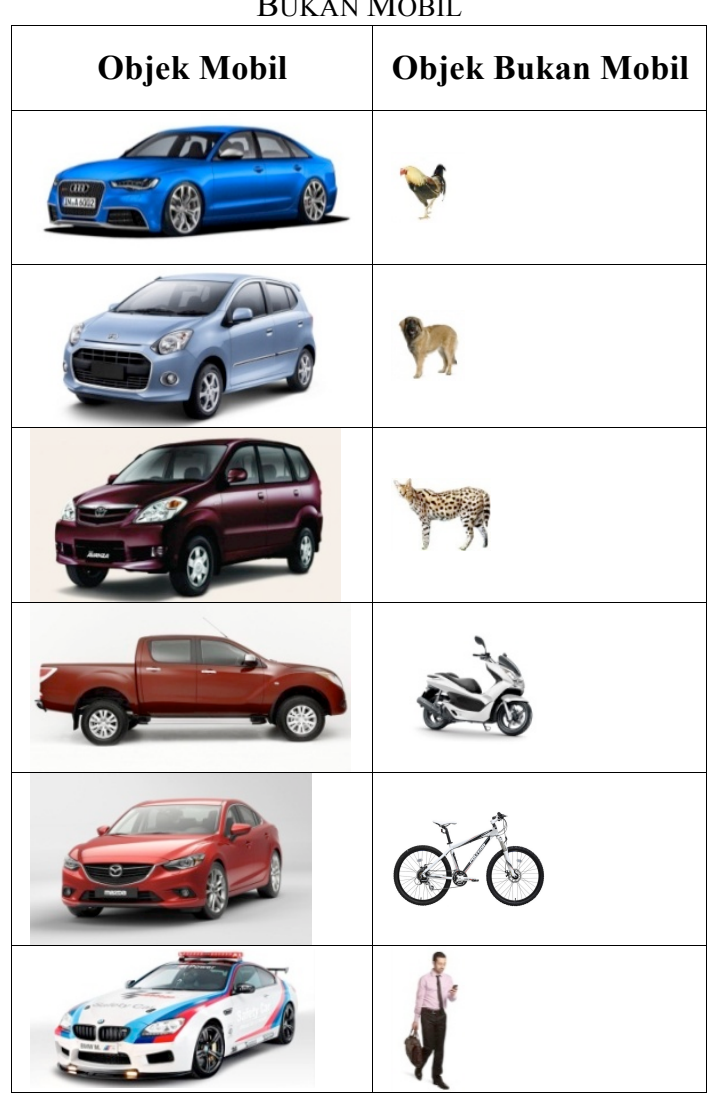

B. Batasan Aplikasi

Aplikasi yang dikerjakan memiliki beberapa batasan yaitu, gambar yang digunakan berupa gambar dengan objek mobil dan gambar dengan objek bukan mobil yang di print dengan ukuran A4 $(21 \mathrm{~cm} \quad X \quad 29.7 \mathrm{~cm})$, Aplikasi yang dikembangkan dapat mendeteksi objek mobil dan objek bukan mobil, mobil yang dapat dideteksi berupa mobil pribadi atau mobil niaga (bukan mobil angkutan seperti truk).

\section{Gambaran Umum Aplikasi}

Secara umum aplikasi yang dibangun memiliki beberapa tahapan pekerjaan yaitu:

\section{Akuisisi Citra}

Akuisisi citra adalah tahap mengambil sebuah pemandangan pada suatu waktu tertentu dari stream gambar yang diberikan oleh webcam. Pada penelitian ini pengambilan gambar menggunakan webcam dengan resolusi 640 x 480 piksel. Akuisisi citra sangat menentukan keberhasilan sistem dalam mengenali objek berupa mobil atau bukan mobil. Ada beberapa hal yang perlu diperhatikan agar citra yang dihasilkan memiliki kualitas yang baik.
Jarak objek dengan webcam, tingkat kemiringan webcam dan cahaya ada saat pengambilan gambar, ketiga faktor ini adalah faktor yang diusahakan konstan. Gambar 3 memperlihatkan diagram alir proses akuisisi citra

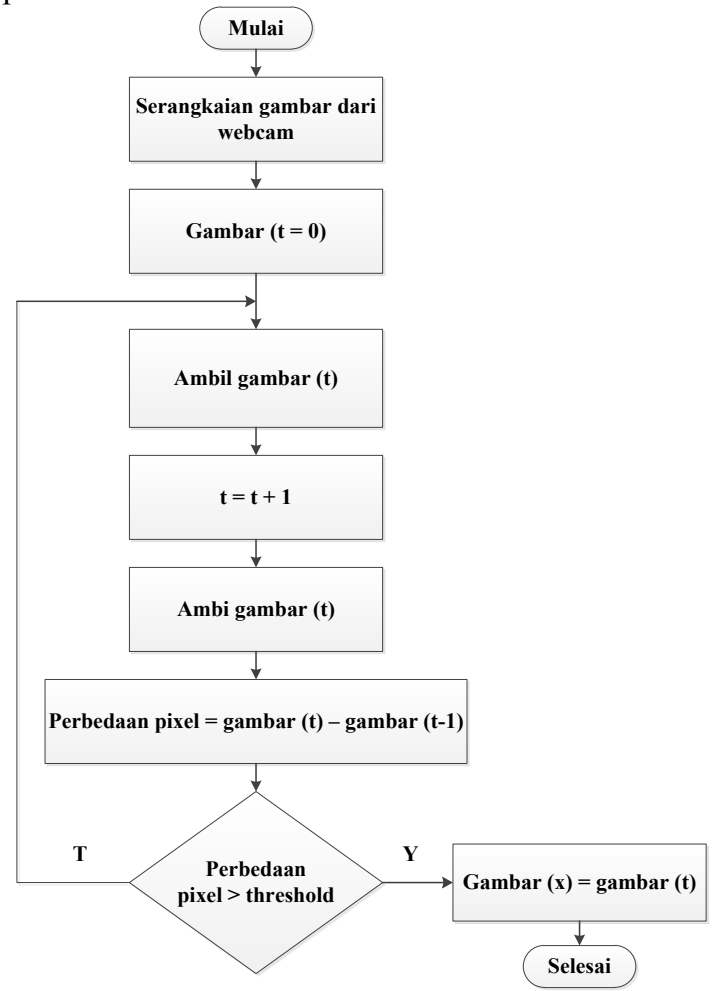

Gambar 3 Diagram Alir Proses Akuisisi Citra

2. Ekstraksi Ciri Citra dan Menyimpan Ciri Kedalam Basis Data

Proses yang dilakukan setelah melakukan akuisisi citra adalah melakukan ekstraksi ciri dari citra, ciri yang digunakan untuk mewakili citra adalah ciri tekstur dan bentuk, yang masingmasing diekstrak menggunakan Wavelet Haar dan Mommen Invarian,

Ciri tekstur dari citra didapatkan dengan melakukan transformasi wavelet diskrit terhadap citra hasil akuisisi, hasil dari transformasi ini adalah 7 buah subband, dari setiap subband diekstraksi sebuah ciri mengunakan persamaan (11) dan (12), hasil ekstraksi ciri ini adalah vektor ciri tekstur dari citra terakkuisisi dengan panjan vektor adalah 14.

Ciri bentuk dari citra didapatkan dengan mencari mommen dari gambar yang telah diakuisisi, persamaan (2) sampai dengan persamaan (8) diaplikasikan terhadap citra yang terlebih dahulu telah diubah menjadi citra biner, 
hasil dari ekstraksi ciri ini adalah 7 buah ciri bentuk yang mewakili sebuah citra.

Kedua vektor ciri digabungkan menjadi sebuah vektor ciri yang memiliki panjang 21 ciri yang mewakili tekstur dan bentuk dari citra yang diakuisisi. Vektor ciri ini disimpan dalam basis data dan digunakan sebagai data latih untuk proses berikutnya.

\section{Pelatihan Ciri dalam Basis Data Menggunakan} LVQ

Dengan memiliki fitur yang telah disimpan dalam basis data maka proses pelatihan dapat dilakukan, proses pelatihan dilakukan dengan menggunakan metode LVQ yang melatih 2 buah bobot yaitu 'mobil' dan 'bukan mobil', bobot ini yang digunakan untuk melakukan klasifikasi terhadap objek yang tertangkap oleh kamera.

\section{Proses Mendeteksi Objek yang Tertangkap} Kamera

Proses mendeteksi objek adalah proses klasifikasi menggunakan bobot yang telah didapatkan dari hasil pelatihan pada proses sebelunya, citra yang telah diakuisisi diekstraksi cirinya sama dengan objek yang dijadikan data latih, hanya saja vektor ciri dari objek yang datang tidak disimpan kedalam basis data, jarak Euclidean dari vektor ciri objek yang ingin dideteksi dihitung terhadap bobot mobil dan bukan mobil yang telah disimpan dalam basis data, jarak terkecil menandakan bahwa objek tersebut merupakan salah satu anggota baik kelas 'mobil' atau kelas 'bukan mobil'.

\section{IMPLEMENTASI DAN HASIL PENGUJIAN}

Hasil implementasi dari rancangan aplikasi membentuk sebuah interface seperti pada gambar

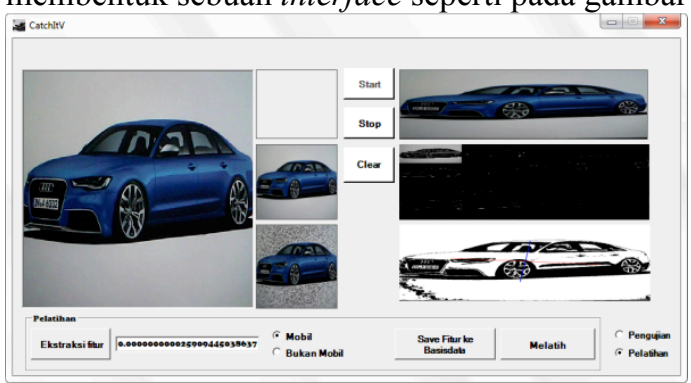

Gambar 4 Tampilan Aplikasi Saat Dijalankan

Menggunakan aplikasi yang telah dibangun proses pengujian dilakukan dengan variasi jumlah data latih dalam basis data dan jumlah epoch pada saat melatih bobot menggunaan $L V Q$, formasi data uji dan data latih menggunakan formasi yang telah dijelaskan pada bagian 'Data Penelitian'. Hasil pengujian dapat dilihat pada Tabel 2.

TABEL 2 Tabel Hasil Pengujian Dengan Variasi Jumlah Epoch Dengan Data Latih 120

\begin{tabular}{|c|c|c|c|c|c|c|}
\hline \multirow[b]{2}{*}{$\begin{array}{c}\text { Jenis } \\
\text { Obje } \\
\text { k }\end{array}$} & \multicolumn{2}{|c|}{$\begin{array}{c}\text { Sumber } \\
\text { Objek }\end{array}$} & \multirow[b]{2}{*}{$\begin{array}{c}\text { Epoc } \\
\text { h }\end{array}$} & \multirow{2}{*}{$\begin{array}{c}\text { Ban } \\
\text { yak } \\
\text { Pen } \\
\text { guji } \\
\text { an }\end{array}$} & \multirow[b]{2}{*}{$\begin{array}{c}\text { Terdef } \\
\text { inisi } \\
\text { Tepat }\end{array}$} & \multirow[b]{2}{*}{$\begin{array}{l}\text { Terde } \\
\text { finisi } \\
\text { Salah }\end{array}$} \\
\hline & $\begin{array}{c}\text { Data } \\
\text { Lati } \\
\mathbf{h}\end{array}$ & $\begin{array}{c}\text { Luar } \\
\text { Data } \\
\text { Lati } \\
\text { h }\end{array}$ & & & & \\
\hline $\mathrm{M}$ & $\sqrt{ }$ & & 100 & 30 & 30 & 0 \\
\hline $\mathrm{M}$ & $\sqrt{ }$ & & 500 & 30 & 29 & 1 \\
\hline $\mathrm{M}$ & $\sqrt{ }$ & & 1000 & 30 & 28 & 2 \\
\hline M & & $\sqrt{ }$ & 100 & 30 & 28 & 2 \\
\hline $\mathrm{M}$ & & $\sqrt{ }$ & 500 & 30 & 22 & 8 \\
\hline $\mathrm{M}$ & & $\sqrt{ }$ & 1000 & 30 & 24 & 6 \\
\hline $\mathrm{BM}$ & $\sqrt{ }$ & & 100 & 30 & 25 & 5 \\
\hline $\mathrm{BM}$ & $\sqrt{ }$ & & 500 & 30 & 29 & 1 \\
\hline $\mathrm{BM}$ & $\sqrt{ }$ & & 1000 & 30 & 30 & 0 \\
\hline $\mathrm{BM}$ & & $\sqrt{ }$ & 100 & 30 & 15 & 15 \\
\hline $\mathrm{BM}$ & & $\sqrt{ }$ & 500 & 30 & 25 & 5 \\
\hline $\mathrm{BM}$ & & $\sqrt{ }$ & 1000 & 30 & 18 & 12 \\
\hline$M$ & $\sqrt{ }$ & & 100 & 60 & 60 & 0 \\
\hline $\mathrm{M}$ & $\sqrt{ }$ & & 500 & 60 & 58 & 2 \\
\hline $\mathrm{M}$ & $\sqrt{ }$ & & 1000 & 60 & 60 & 0 \\
\hline $\mathrm{M}$ & & $\sqrt{ }$ & 100 & 60 & 44 & 16 \\
\hline $\mathrm{M}$ & & $\sqrt{ }$ & 500 & 60 & 32 & 28 \\
\hline$M$ & & $\sqrt{ }$ & 1000 & 60 & 42 & 18 \\
\hline $\mathrm{BM}$ & $\sqrt{ }$ & & 100 & 60 & 44 & 16 \\
\hline $\mathrm{BM}$ & $\sqrt{ }$ & & 500 & 60 & 59 & 1 \\
\hline $\mathrm{BM}$ & $\sqrt{ }$ & & 1000 & 60 & 60 & 0 \\
\hline $\mathrm{BM}$ & & $\sqrt{ }$ & 100 & 60 & 27 & 33 \\
\hline $\mathrm{BM}$ & & $\sqrt{ }$ & 500 & 60 & 39 & 21 \\
\hline $\mathrm{BM}$ & & $\sqrt{ }$ & 1000 & 60 & 44 & 16 \\
\hline
\end{tabular}

Ket : M-Mobil ; BM-Bukan Mobil

\section{ANALISIS HASIL PENGUJIAN}

Hasil pengujian memberikan gambaran tentang performa kerja dari aplikasi yang dikembangkan Gambar 5 menampilkan grafik hasil pengujian kinerja sistem menggunakan data uji sebanyak 3 di ambil dari luar data latih di uji masing - masing sebanyak 10 kali dengan epoch 100, 500, dan 1000 untuk target mobil.

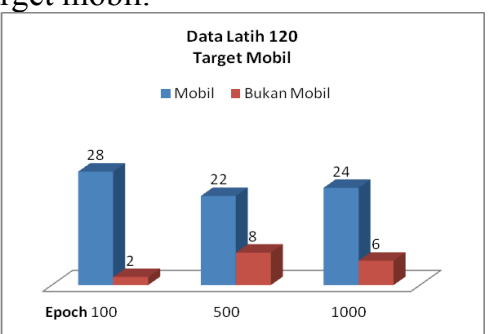

Gambar 5 Grafik hasil pengujian kinerja dengan target mobil

Gambar 6 menampilkan grafik hasil pengujian kinerja sistem menggunakan data uji sebanyak 3 
diambil dari data latih diuji masing - masing sebanyak 10 kali dengan epoch 100, 500, dan 1000 untuk target bukan mobil.

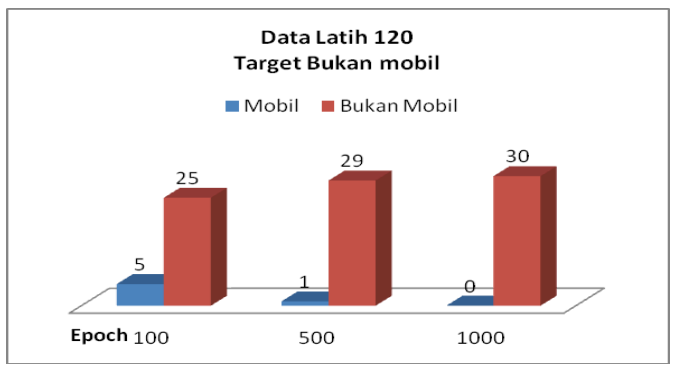

Gambar 6 Grafik hasil pengujian kinerja dengan target bukan mobil

Pengujian juga dilakukan dengan variasi jumlah data latih pada basis data, hasil dari keseluruhan pengujian dapat dilihat pada Tabel 3.

TABEL 3 TABEL RATA-RATA PRESISI APLIKASI YANG DIKEMBANGKAN

\begin{tabular}{|c|c|c|c|c|c|c|c|c|}
\hline \multirow{4}{*}{$\begin{array}{l}\text { Tar } \\
\text { get } \\
\text { uji }\end{array}$} & \multirow{4}{*}{$\begin{array}{l}\text { Dat } \\
\text { a }\end{array}$} & \multicolumn{6}{|c|}{ Nilai presisi (\%) } & \multirow{4}{*}{$\begin{array}{l}\text { Rata- } \\
\text { rata } \\
\text { nilai } \\
\text { presisi }\end{array}$} \\
\hline & & \multirow{2}{*}{\multicolumn{3}{|c|}{$\frac{10 \text { kali pengujian }}{\text { Epoch }}$}} & \multirow{2}{*}{\multicolumn{3}{|c|}{$\frac{20 \text { kali pengujian }}{\text { epoch }}$}} & \\
\hline & & & & & & & & \\
\hline & & 100 & 500 & $\begin{array}{l}100 \\
0\end{array}$ & 100 & 500 & 1000 & \\
\hline M & \multirow{2}{*}{120} & $\begin{array}{l}96, \\
67\end{array}$ & 85 & $\begin{array}{l}86,8 \\
7 \\
\end{array}$ & $\begin{array}{l}86, \\
67\end{array}$ & 75 & 85 & 85,86 \\
\hline BM & & $\begin{array}{l}66, \\
67 \\
\end{array}$ & 90 & 80 & $\begin{array}{l}59 \\
16 \\
\end{array}$ & $\begin{array}{l}81, \\
67 \\
\end{array}$ & 86,67 & 77,36 \\
\hline M & \multirow{2}{*}{180} & $\begin{array}{l}86, \\
67 \\
\end{array}$ & $\begin{array}{l}78, \\
34 \\
\end{array}$ & 80 & $\begin{array}{l}86, \\
67 \\
\end{array}$ & $\begin{array}{l}75, \\
84 \\
\end{array}$ & 80 & 81,25 \\
\hline BM & & 50 & $\begin{array}{l}83, \\
34\end{array}$ & $\begin{array}{l}86,6 \\
7 \\
\end{array}$ & 45 & $\begin{array}{l}76, \\
67\end{array}$ & 85,84 & 71,25 \\
\hline M & \multirow{2}{*}{240} & 85 & $\begin{array}{l}81, \\
67 \\
\end{array}$ & $\begin{array}{l}91,6 \\
7 \\
\end{array}$ & $\begin{array}{l}85, \\
84 \\
\end{array}$ & $\begin{array}{l}75, \\
84 \\
\end{array}$ & 93,34 & 85,56 \\
\hline BM & & $\begin{array}{l}86, \\
67\end{array}$ & 10 & 3,34 & $\begin{array}{l}90, \\
84\end{array}$ & 55 & 48,34 & 49,03 \\
\hline
\end{tabular}

Dari Tabel 3 dapat disimpulkan nilai rata-rata presisi untuk target mobil $84,23 \%$ dan nilai ratarata presisi untuk target bukan mobil 65,88\%.

\section{PENUTUP}

Setelah melalui serangkaian perancangan dan percobaan maka didapatkan beberapa point penting sebagai rangkuman kegiatan penelitian iniataupun saran pengembangan untuk penelitian lanjutan, yaitu.

1. Aplikasi yang dibangun dibagi menjadi tiga bagian yaitu proses akuisisi citra, proses akuisisi citra dari objek berupa gambar menjadi sekumpulan fitur yang selanjutnya di ekstraksi dengan metode wavelet untuk fitur tekstur dan metode momen invarian untuk fitur bentuk. Fitur yang sudah di ekstraksi selanjutnya disimpan ke basisdata. Proses pelatihan bobot fitur dalam basisdata dilakukan dengan variasi epoch 100, 500 dan 1000. Variasi epoch dilakukan untuk mendapatkan nilai tertinggi dari fitur. Proses pengujian menggunakan data uji dari dalam data latih dan dari luar data latih dengan variasi jumlah data latih sebanyak 120, 180 dan 240 fitur.

2. Performa sistem yang telah di bangun di uji dengan menggunakan data uji dari dalam data latih dan dari luar data latih, nilai rata-rata presisi untuk target mobil $84,23 \%$ dan nilai rata-rata presisi untuk target bukan mobil $65,88 \%$.

3. Hasil dari sistem kamera pengawas ini untuk objek bukan mobil memang kurang memuaskan dan presisinya masih dapat ditingkatkan dengan menambahkan metode atau pendekatan baru baik dalam teknik ekstraksi fitur maupun akuisisi gambar dan pelatihan.

\section{REFERENSI}

[1] Amelia, M. Sarwoko, Tengku Ahmad Riza, Perancangan Sistem Deteksi Jenis Kendaraan Bermotor Berbasis Mikrokontroler (Studi Kasus : Jalur Transjakarta). Jurnal Teknologi, Vol ume 6, Nomor 1, Hal 90-97, 2013.

[2] Setiawan Hadi, Yoeshua Rekha Samara.Hibah Fundamental 2011-2012 nomor kontrak DIPA DIKTI 0541/02304.1/00/2011. dapat diakses melalui alamat web:http://dspace.library.uph.edu:8080/bitstr eam/123456789/898/2/jiik-08-02-2012deteksi_objek_kendaraan_pada.pdf

[3] Sanjay Silakari, Mahesh Motwani, Manish Maheshwari. Color Image Clustering using Block Truncation Algorithm. IJCSI International Journal of Computer Science Issues, Vol. 4, No. 2, Hal 31-36,2009.

[4] Putra, Darma. 2009. "Sistem Biometrika". Yogyakarta. Andi Offset

[5] R. Coifman, Y. Meyer, S. Quake, and V. Wickerhauser,"Signal processing and compression with wavelet packets", Numerical Algorithms Research Group,New Haven, CT: Yale University, 1990.

[6] Fausett, Laurene. 1994. "Fundamentals of Neural Networks". Prentice-Hall

[7] Hagan, Martin T. DKK. 1996. "Neural Network Design”. USA: PWS Publishing Company 